\section{Reduced inbreeding depression in separate generations of onions}

\begin{abstract}
Mitigating reductions in vigor in onion seed production has been a great challenge to breeding programs. Therefore, we compared the effects of inbreeding depression among populations obtained from self-fertilization and crossbreeding with two and three plants. We evaluated eleven populations and three breeding methods (two and three-plant crossbreeding, and self-fertilization of one plant) and measured the characteristics related to seed yield (plant appearance, stem vigor, number of umbels, flowering uniformity, fruit setting, and resistance to Alternaria) from 2014 to 2015. Thirteen RAPD molecular markers were used to determine the genetic divergence among populations derived from different breeding methods. We found that inbreeding depression affects plant vigor in early generations that have greater heterozygosity. Three-plant crossbreeding results in greater seed yield in populations with low levels of inbreeding. The populations obtained from self-fertilization and two- and threeplant crossbreeding were genetically similar, demonstrating the efficiency of obtaining inbred lines without genetic divergence.
\end{abstract}

Keywords: Allium cepa L., intercrossing, genetic segregation, crossbreeding, endogamic level.

\section{INTRODUCTION}

Onions (Allium cepa L.) are a rich source of phytochemicals, such as carotenoids, copaenes, flavonoids, minerals, phenolics, phytoestrogens, terpenoids, vitamins, anthocyanins and amino acids (Ouyang et al. 2017), which are all beneficial to human health. Some flavonols, such as quercetin, have antioxidant, anticancer and sedative effects and may have relevance in the treatment of Alzheimer's disease and diabetes (Nile et al. 2018).

More than half of the onions produced in Brazil are grown on family farms of less than 20 hectares in area (Nunes et al. 2014). Hybrid onions accounted for $40 \%$ of the total production with the potential to increase due to uniformity in bulb color, shape, size, and substantially greater yields (Havey and Kohn 2017, Khar et al. 2018), relative to parent varieties (Schnable and Springer 2013).

Hybrids are traditionally bred from parent lines using the pedigree method. Despite the pronounced advantage of heterosis in hybrids (Quartieiro et al. 2014, Petropoulos et al. 2015, Vajire et al. 2017), the effects of inbreeding depression are significant (Ayroles et al. 2009), and consequently create a major obstacle to hybrid seed production. Inbreeding depression refers to a decline in the
Crop Breeding and Applied Biotechnology 20(2): e26402026, 2020 Brazilian Society of Plant Breeding. Printed in Brazil http://dx.doi.org/10.1590/198470332020v20n2a22

70332020v20n2a22


. 
expression of quantitative characters that are caused by greater homozygosity and result in decreased plant vigor, bulb size and seed yield (Hallauer et al. 2010).

Thus, new breeding methods must be developed to mitigate these losses in vigor. Studies have shown that crossbreeding may mitigate inbreeding depression in natural populations (Porcher and Lande 2013, Devaux et al. 2014, Porcher and Lande 2016). The objective of this study was to evaluate new breeding methods in separate onion populations that could mitigate losses in vigor.

\section{MATERIAL AND METHODS}

\section{Location}

The experiments were carried out over two consecutive years (2014-2015) at the Experimental Station of Bayer Vegetable Seeds (lat $18^{\circ} 43^{\prime} 57.6^{\prime \prime} \mathrm{S}$, long $48^{\circ} 24^{\prime} 03.3^{\prime \prime} \mathrm{W}$, alt $872 \mathrm{~m}$ asl), in Uberlandia, MG, Brazil. The climate of the region was classified as Aw (Köppen) with dry winters and wet summers. Molecular analysis was performed at the Laboratório de Análise de Sementes e Recursos Genéticos (LAGEN) of the Federal University of Uberlandia, Monte Carmelo-MG campus.

\section{Origin and breeding of onion populations}

The onion populations used in this study belonged to the breeding program of Bayer Vegetable Seeds in Brazil (Table 1). Populations 1 through 12 were obtained from generations that already had a moderate level of inbreeding. Populations 1 to 3 originated from the self-fertilization of an $F_{2} S_{2}$ background plant "GR $\times$ GR" population 1 (pop. 1) and crossbreeding two and three $\mathrm{F}_{2} \mathrm{~S}_{2}$ plants from the same background (pop. 2 and 3, respectively). Populations 4 to 6 were obtained from the self-fertilization of an $S_{3}$ plant from an "IP" background (pop. 4) and crossbreeding two and three $S_{3}$ plants from the same background (pop. 5 and 6, respectively). Populations 7 to 12 originated from the self-fertilization

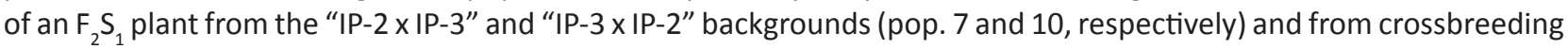
two and three plants from the same "IP-2 x IP-3" backgrounds (pop. 8 and 9, respectively) and "IP-3 x IP-2" (pop. 11 and 12 , respectively). All populations (1-12) were obtained from individuals with similar parentage and can therefore be classified as moderately inbred. Similarly, populations 13 to 33 (Table 1), with a low level of inbreeding, were obtained from seven different backgrounds as follows: individual plants from F2 populations were self-fertilized (pop. 13, 16, 19, $22,25,28$, and 31), interbred using two plants (pop. 14, 17, 20, 23, 26, 29, and 32) and interbred using three plants (pop. 15, 18, 21, 24, 27, 30, and 33).

Six onion bulbs were sampled from each distinct background group. One bulb was self-fertilized $\left(A_{1}\right)$, and two and three other bulbs were interbred $\left(B_{2}\right.$ and $C_{3}$, respectively). After planting the bulbs and subsequent budding, the plants were isolated in cages at the stage of flowering. House flies (Musca domestica) were used for pollination and subsequent seed production. These steps took place from 2012 to 2013. In 2014, the seeds were sown and transplanted and then used to establish the first field crop, which was used for agronomic evaluations. After harvesting, the bulbs were vernalized in a cold room and then planted in 2015 to establish the second field crop. Samples were then collected from this second crop and used for molecular analyses and seed yield evaluations.

\section{Setup and evaluation of agronomic experiments}

The plants in the first field crop (seed to bulb phase) were sown on March 19, 2014 and transplanted on April 27, 2014. The beds were prepared and fertilized as recommended for onions. The treatments represented the different breeding methods (self-fertilization of one plant (A1) and crossbreeding of two (B2) and three plants (C3) from 11 different genetic backgrounds, grouped according to the average level of inbreeding (moderate and low) (Table 1).

The experiment was set up in a randomized block design with three repetitions. Each plot consisted of a bed (1.0 $\mathrm{m} \times 0.9 \mathrm{~m}$ ) with five rows spaced at 0.20 meters and plants spaced $5 \mathrm{~cm}$ apart, totaling 100 plants per plot. Evaluations were made for each plot. Subjective characteristics were assigned a grade from 1 (worst) to 9 (best).

Plant vigor: Plant vigor was graded (1-9) at 90 and 120 days after sowing (DAS) and leaf diameter, plant height, and number of leaves were also considered at different stages. Plant height $(\mathrm{cm})$ was determined at 150 DAS as the mean 
height of the three centermost plants in each plot. Pseudostem diameter (neck'): Neck diameter was graded from 1 (thick) to 9 (thin). Plant architecture: Graded from 1 (prostrate) to 9 (erect). Cycle: Measured in days from sowing to top-down (more than $50 \%$ top-down). Botrytis squamosa severity was graded according to severity from 1 (least severe) to 9 (most severe).

The following bulb evaluations were made after harvesting:

Tunic color: Graded from 1 to 9, where 9 represents dark-brown tunic. Firmness: Graded from 1 to 9, where higher numbers represent firmer bulbs. Mean bulb weight: Total bulb weight (g) within a plot divided by the total bulb number within the same plot. Globular bulbs: Bulbs were classified by shape as either globular (group 1) or flat (group 2). The percentage of globular bulbs was then calculated for each plot. Commercial grade bulbs: Bulbs from each plot were classified according to quality (Class I, Class II, Class III, Class IV and Class V) using the transverse diameter criteria specified by the Ministério da Agricultura Pecuária e Abastecimento: Class I (bulb diameter, 15-35 mm), Class II (35-50 $\mathrm{mm})$, Class III (50-75 mm), Class IV (75-90 mm), and Class V (>90 mm). The percentages of commercial grade bulbs in classes II, III, and IV were then calculated. Total yield: The weight of the bulbs from each plot was corrected and expressed as kg per plot.

After evaluation, the bulbs were stored and vernalized (approximately three months) until the second planting was used to determine seed yield. The bulbs were transplanted in the field (bulb to seed phase) on April 30, 2015.

Seed yield was evaluated using the following characteristics:

General plant appearance: The general appearance of the plants was graded (1-9) at 30, 60, and 90 DAT (days after transplanting) based on the general stem height, stem diameter, and umbel size within a plot. Lower grades were assigned for lower values and higher grades for higher values. Stem vigor: Graded from 1 (low vigor) to 9 (high vigor). Umbel vigor: Graded from 1 (low vigor) to 9 (high vigor). Umbel number: Total number of umbels per plot right before seed harvesting. Flowering uniformity: The number of umbels with open flowers in each plot was graded weekly from 1 (least uniform) to 9 (most uniform). Fruit setting: graded from 1 (low setting) to 9 (high setting). Resistance to Alternaria: graded from 1 (least Alternaria porri severity) to 9 (greatest severity). Seed mass per umbel: mean mass (g) of seeds per umbel within a plot.

\section{Statistical procedures}

The results were submitted to analysis of variance and contrasts of interest were performed using the Scheffe test to identify possible differences (at the $\alpha=0.05$ significance level) between the breeding methods in three different segregation states: all backgrounds, only backgrounds with low levels of inbreeding, and only backgrounds with moderate levels of inbreeding. The data were analyzed using Sisvar (Ferreira 2011).

\section{DNA extraction and molecular evaluation}

Molecular analyses were performed on twelve inbred lines (populations 1-12, Table 1) and three plants per plot, for a total of 36 samples. These 12 treatments came from the GR x GR, IP-1, IP-2 x IP-3 (and its reciprocal) backgrounds in different segregation states of the $A_{1}, B_{2}$, and $C_{3}$ populations. Therefore, these treatments are representative of the other treatments and can be used to compare different generations with low and moderate inbreeding and check for genetic divergence using RAPD markers. The bulbs were transplanted in April 2015. Approximately 20 days later, leaf bulk was determined from the three samples collected from each of the three plants (young leaves from the initial bulb shoots) for each of the twelve treatments/populations.

Afterwards, three DNA samples from the same population and generations were combined, yielding 12 samples. The collected tissue was frozen in liquid nitrogen and lyophilized. DNA was extracted according to a modified version of the protocol outlined by Ferreira and Grattapaglia (1996). The samples were tested against 13 different primers (OPA14, OPA16, OPA16, OPB11, OPB11, OPC08, OPC08, OPC09, OPC11, OPC13, ODP03, OPE10, OPF19) (Operon Technologies kits) (Table 4).

For clarity, the three populations were coded as follows: $A 1$, individual self-fertilized populations $\left(F_{2} S_{3^{\prime}}, S_{4^{\prime}}, F_{2} S_{2}\right.$ and $\mathrm{F}_{2} \mathrm{~S}_{1}$ ); $\mathrm{B}_{2}$, two-plant "SIB2" crossbred populations ( $\mathrm{F}_{2} \mathrm{~S}_{2} \mathrm{SIB} 2$ pl., $\mathrm{S}_{3} \mathrm{SIB} 2 \mathrm{pl}$., $\mathrm{F}_{2} \mathrm{~S}_{1} \mathrm{SIB} 2 \mathrm{pl}$., and $\mathrm{F}_{2} \mathrm{SIB} 2 \mathrm{pl}$.); $\mathrm{C}_{3}$, three-plant "SIB3" crossbred populations ( $F_{2} S_{2} S I B 3$ pl., $S_{3} S I B 3 p l ., F_{2} S_{1} S I B 3 p l$. , and $\left.F_{2} S I B 3 p l.\right)$ (Table 1). 
Contrasts were made in three ways using the data and evaluation notes: I, data only from populations with moderate inbreeding (populations 1-12, Table 1); II, data from populations with low levels of inbreeding (populations 13-33); and III, data from populations with moderate and low levels of inbreeding (populations 1-33). The resulting contrasts were expressed as $\left|A_{1} \times B_{2}\right|,\left|A_{1} \times C_{3}\right|,\left|B_{2} \times C_{3}\right|$, and $\left|A_{1} \times B_{2}+C_{3}\right|$.

\section{RESULTS AND DISCUSSION}

\section{Contrasts involving populations with moderate inbreeding}

The breeding method did not influence plant height and vigor at 90 and 120 DAS (Table 1). The $\left|B_{2} \times C_{3}\right|$ contrast, where two and three plants were separately crossbred, showed that pseudostems (necks) were larger in the threeplant group than in the two-plant group. This may be due to the greater heterozygosity of the three-plant population (Table 2). No significant inbreeding effects were found among the individual self-fertilized plant populations and the two- and/or three-plant crossbred populations regarding plant architecture, cycle, Botrytis severity, tunic color, bulb firmness, and percentage of commercial-grade bulbs (Table 2).

However, there were significant differences between individual plants and crossbred plants regarding mean bulb weight, percentage of globular bulbs, and total bulb yield per plot (Table 2). Negative contrasts indicate greater vigor (or less depression) in the two- and/or three-plant populations than in the self-fertilized population. Significant contrasts were also found for $A_{1} \times B_{2+} C_{3}$, showing that inbreeding depression in these onion populations was not only confined to early generations, as might be expected. Therefore, as the number of plants increased, the mean bulb weight, percent globular bulbs, and yield also increased, due to greater heterozygosity (Table 2).

In some cases, the general appearance of the stems was significantly affected at 30,60 , and 90 days when more plants were crossbred (Table 3 ). There were also significant differences in the $\left|B_{2} \times C_{3}\right|$ (general stem appearance at 60 days) and $\left|\mathrm{A}_{1} \times \mathrm{B}_{2+} \mathrm{C}_{3}\right|$ (at 30,60 , and 90 days, in addition to stem vigor) contrasts. However, these differences were in favor of the self-fertilized populations (positive contrasts). This may have occurred because these populations had already undergone a moderate degree of inbreeding. Except for the $\left|B_{2} \times C_{3}\right|$ contrast (-0.58), these results demonstrate that general stem appearance improved when more plants were crossbred.

Stem vigor also did not appear to suffer as much from additional inbreeding (a further generation of selffertilization) when moderate inbreeding was already present $\left(\left|A_{1} \times B_{2}\right|=0.75\right.$ and $\left|A_{1} \times B_{2}+C_{3}\right|=0.54$ (Table 3 ). Flowering uniformity was lower in three-plant crossbred populations than in two-plant populations $\left(\left|B_{2} \times C_{3}\right|\right.$ $=-0.58)$. No significant differences were found in the contrasts for the other characteristics related to seed yield (Table 2).

Table 1. Different genetic generations of onion populations and their respective codes, backgrounds, and average level of inbreeding

\begin{tabular}{|c|c|c|c|}
\hline Population* & Code & Background & Average level of inbreeding \\
\hline $\mathrm{F}_{2} \mathrm{~S}_{3}$ & $\mathrm{~A}_{1}$ & $\mathrm{GR} \times \mathrm{GR}^{1}$ & \\
\hline $\mathrm{F}_{2} \mathrm{~S}_{2} \mathrm{SIB} 2$ plants & $\mathrm{B}_{2}$ & $\mathrm{GR} \times \mathrm{GR}$ & \\
\hline $\mathrm{F}_{2} \mathrm{~S}_{2} \mathrm{SIB} 3$ plants & $\mathrm{C}_{3}$ & $\mathrm{GR} \times \mathrm{GR}$ & \\
\hline $\mathrm{S}_{4}$ & $\mathrm{~A}_{1}$ & $I P^{2}-1$ & \\
\hline $\mathrm{S}_{3} \mathrm{SIB} 2$ plants & $\mathrm{B}_{2}$ & IP-1 & \\
\hline $\mathrm{S}_{3}$ SIB3plants & $\mathrm{C}_{3}$ & IP-1 & Moderate \\
\hline $\mathrm{F}_{2} \mathrm{~S}_{2}$ & $A_{1}$ & IP-2 x IP-3 & \\
\hline $\mathrm{F}_{2} \mathrm{~S}_{1} \mathrm{SIB} 2$ plants & $\mathrm{B}_{2}$ & IP-2 $x$ IP-3 & \\
\hline $\mathrm{F}_{2} \mathrm{~S}_{1} \mathrm{SIB} 3$ plants & $\mathrm{C}_{3}$ & IP-2 x IP-3 & \\
\hline $\mathrm{F}_{2} \mathrm{~S}_{2}$ & $A_{1}$ & IP-3 x IP-2 & \\
\hline $\mathrm{F}_{2} \mathrm{~S}_{1} \mathrm{SIB} 2$ plants & $\mathrm{B}_{2}$ & IP-3 x IP-2 & \\
\hline $\mathrm{F}_{2} \mathrm{~S}_{1} \mathrm{SIB} 3$ plants & $\mathrm{C}_{3}$ & IP-3 x IP-2 & \\
\hline $\mathrm{F}_{2} \mathrm{~S}_{1}$ & $\mathrm{~A}_{1}$ & $\mathrm{BUC}^{3}$ & \\
\hline $\mathrm{F}_{2} \mathrm{SIB} 2$ plants & $\mathrm{B}_{2}$ & $B \cup C$ & \\
\hline $\mathrm{F}_{2}$ SIB3plants & $\mathrm{C}_{3}$ & BUC & \\
\hline $\mathrm{F}_{2} \mathrm{~S}_{1}$ & $A_{1}$ & GR $\times$ IP-1 & \\
\hline $\mathrm{F}_{2} \mathrm{SIB} 2$ plants & $\mathrm{B}_{2}$ & GR $\times$ IP-1 & \\
\hline $\mathrm{F}_{2} \mathrm{SIB} 3$ plants & $\mathrm{C}_{3}$ & GR $\times$ IP-1 & \\
\hline $\mathrm{F}_{2} \mathrm{~S}_{1}$ & $A_{1}$ & $\mathrm{GR} \times \mathrm{BOT}^{4}-1$ & \\
\hline $\mathrm{F}_{2} \mathrm{SIB} 2$ plants & $\mathrm{B}_{2}$ & GR x BOT-1 & \\
\hline $\mathrm{F}_{2} \mathrm{SIB} 3$ plants & $\mathrm{C}_{3}$ & GR x BOT-1 & \\
\hline $\mathrm{F}_{2} \mathrm{~S}_{1}$ & $A_{1}$ & GR x BOT-2 & Low \\
\hline $\mathrm{F}_{2} \mathrm{SIB} 2$ plants & $\mathrm{B}_{2}$ & GR x BOT-2 & \\
\hline $\mathrm{F}_{2} \mathrm{SIB} 3$ plants & $\mathrm{C}_{3}$ & GR x BOT-2 & \\
\hline $\mathrm{F}_{2} \mathrm{~S}_{1}$ & $A_{1}$ & GR x BOT-3 & \\
\hline $\mathrm{F}_{2} \mathrm{SIB} 2$ plants & $\mathrm{B}_{2}$ & GR x BOT-3 & \\
\hline $\mathrm{F}_{2} \mathrm{SIB} 3$ plants & $\mathrm{C}_{3}$ & GR x BOT-3 & \\
\hline $\mathrm{F}_{2} \mathrm{~S}_{1}$ & $\mathrm{~A}_{1}$ & GR x BOT-4 & \\
\hline $\mathrm{F}_{2}$ SIB2plants & $\mathrm{B}_{2}$ & GR x BOT-4 & \\
\hline $\mathrm{F}_{2} \mathrm{SIB} 3$ plants & $\mathrm{C}_{3}$ & GR x BOT-4 & \\
\hline $\mathrm{F}_{2} \mathrm{~S}_{1}$ & $\mathrm{~A}_{1}$ & CR x BOT-1 & \\
\hline $\mathrm{F}_{2} \mathrm{SIB} 2$ plants & $\mathrm{B}_{2}$ & CR x BOT-1 & \\
\hline $\mathrm{F}_{2} \mathrm{SIB} 3$ plants & $\mathrm{C}_{3}$ & CR x BOT-1 & \\
\hline
\end{tabular}

$* \mathrm{~S}$ / indicates the number of self-fertilizations. 
Table 2. Contrasts among 12 populations with moderate inbreeding, regarding characteristics of onion plants and bulbs, and seed production

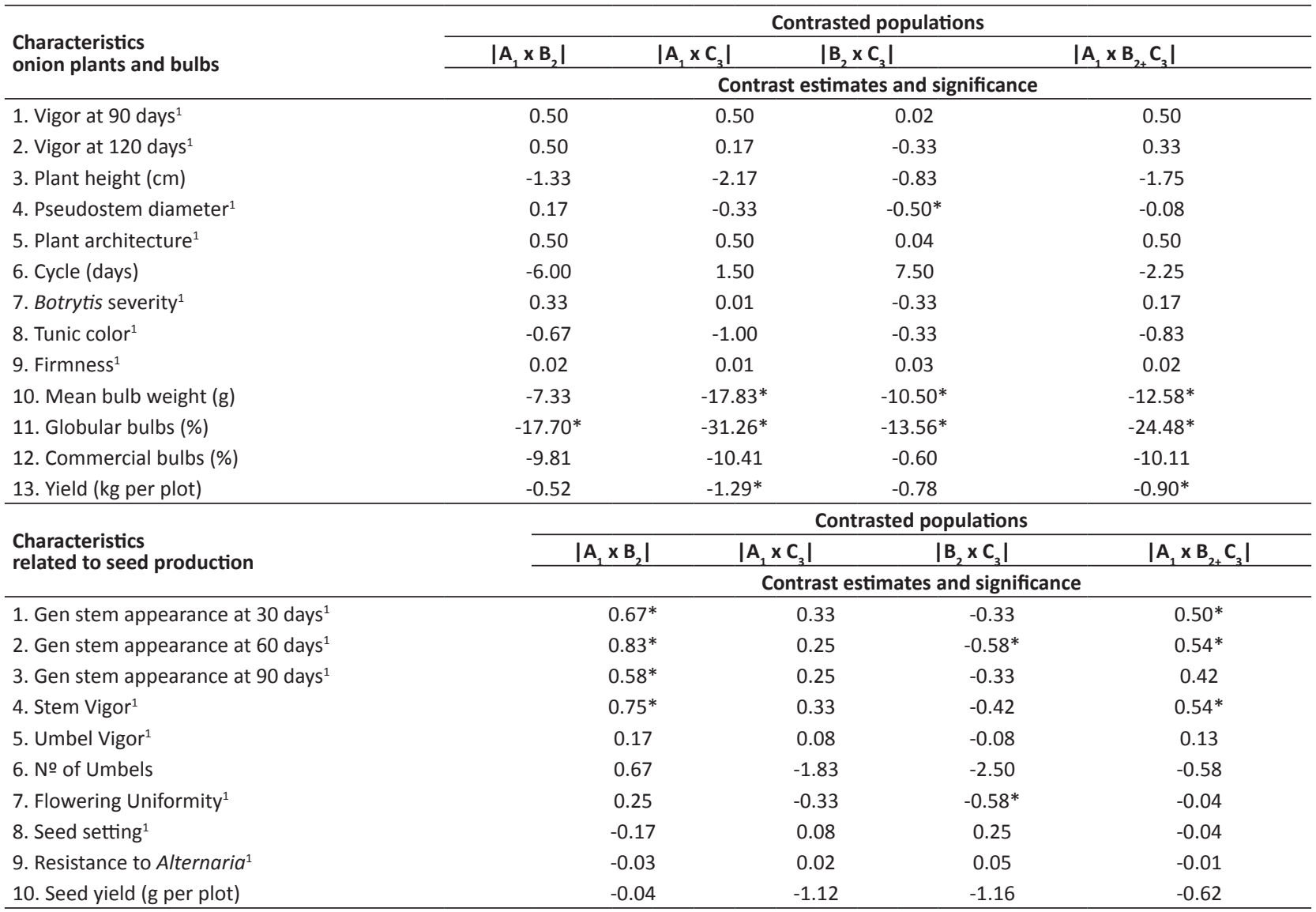

${ }^{1}$ Mean evaluations based on a grading scale from 1 to 9 where 1 represents the lowest or worst values and 9 represents highest or best values. * Contrast estimate is significant according to the Scheffé test at $5 \%$ probability.

\section{Contrasts involving populations with low-level inbreeding}

For plants with low levels of inbreeding (Table 3), plant vigor was significantly greater (negative sign) at 90 DAS in two-plant crossbred populations than in self-fertilized populations. In this case, lower levels of inbreeding may have helped to highlight differences between self-fertilized individuals and two-plant crossbred individuals. In other words, early generations were more susceptible to loss of vigor because of inbreeding depression than those that underwent additional self-fertilization.

Contrasts involving only genotypes with low-level inbreeding showed that the trend for plant and bulb characteristics is repeated with clear increases in the second generation when all materials are segregated. Characteristics related to umbel and plant vigor, such as general appearance at 30,60 and 90 days after transplant (DAT), stem vigor and umbel vigor were significantly higher in the two-plant cross breeding group than in the three-plant group (Table 3 ).

The $\left|A_{1} \times C_{3}\right|$ (8.67) contrast showed a significant difference in crop cycle. Specifically, inbreeding delayed the crop cycle by 8.67 days for the individual self-fertilized population $\left|A_{1}\right|$ compared to the three-plant crossbred population $\left|C_{3}\right|$ (Table 3). Frequently, when bulbs are produced for backcrossing, the first generation $\left(F_{1}\right)$, with greater heterozygosity, produces bulbs earlier than the recurrent parents that have lower heterozygosity.

As in the moderately inbred populations, the contrasts for the low-level inbred populations showed significant differences in mean bulb weight, globular bulb percentage, and bulb yield per plot (Tables 2 and 3). Using more 
plants in cross breeding with inherently higher heterozygosity resulted in higher mean bulb weights, globular bulb percentages, and yields per plot (Table 3). The remaining characteristics mentioned in Table 3 did not show significant contrasts.

Only two factors were significant for contrasts involving populations with low levels of inbreeding and characteristics related to seed yield (Table 3). Seed setting was lower in the self-fertilized population than in the two or three plant crossbred populations $\left(\left|\mathrm{A}_{1} \times \mathrm{B}_{2+} \mathrm{C}_{3}\right|=-0.36^{*}\right)$. Seed yield was $5.15 \mathrm{~g}$ per plot greater in the three-plant crossbred population than in the self-fertilized population $\left|A_{1} \times C_{3}\right|=-5.15^{*}$ (Table 3). Thus, inbreeding from self-fertilization reduced both seed yield and seed setting. However, the remaining characteristics (Table 3 ) were not affected by inbreeding depression in the early generations of self-fertilized plants with low levels of inbreeding.

\section{Contrasts involving populations with moderate and low-level inbreeding}

Table 5 shows the contrasts of data from 33 populations with moderate and low levels of inbreeding. The bulb-yield contrast showed that the crop cycle time of the three-plant crossbreeding population was shorter than that of the twoplant population $\left(\left|\mathrm{B}_{2} \times \mathrm{C}_{3}\right|=8.85\right.$ days) (Table 4).

Furthermore, crossbreeding of two and/or three plants significantly improved characteristics $(p<0.05)$ related to plants and bulbs compared to self-fertilized populations or populations that were crossbred with fewer plants (Table 4). Tables 2 and 3 show that bulb production is significantly earlier when more plants are used in crossbreeding. This

Table 3. Contrast values involving 21 populations with low-level inbreeding and characteristics related to onion plants and bulbs, and seed production



${ }^{1}$ Mean evaluations based on a grading scale from 1 to 9 where 1 represents the lowest or worst values and 9 represents highest or best values. $*$ Contrast estimate is significant according to the Scheffé test at $5 \%$ probability. 
may be explained by the possible fixation of some of the six genes that promote bulbing (Lee 2013) and the reduced representation of individuals in the population. Brewster (1994) also reported that inbreeding delays earliness in lines obtained from repeated self-fertilization.

Data for average bulb weight, globular bulb percent and bulb yield per plot (Tables 2, 3, and 4) show that reductions in inbreeding depression are related to increases in plant numbers. Seed production contrasts were made for populations with moderate and low levels of inbreeding (Table 4). The general stem appearance at 30, 60, and 90 days did not differ between the self-fertilized plants and those that came from two-plant crossbreeding (|A1 x B2 |). However, three-plant crossbreeding did highlight greater inbreeding effects than two-plant crossbreeding $\left(\left|B_{2} \times C_{3}\right|\right)$. These results show that the general stem appearance was not substantially affected by inbreeding.

There was also no significant effect of inbreeding on umbel and stem vigor when comparing self-fertilization and twoplant crossbreeding. Three-plant crossbreeding $\left(\left|\mathrm{B}_{2} \times \mathrm{C}_{3}\right|\right)$ favored greater heterozygosity for these two characteristics and highlighted notable inbreeding depression. Two significant contrasts ( $|\mathrm{A} 1 \times \mathrm{C} 3|=8.50^{*}$ and $\mid \mathrm{A} 1 \times \mathrm{B} 2 \mathrm{C} 3=8.25^{*}$ ) showed that inbreeding had no significant effect on the number of umbels.

The flowering uniformity contrasts $\left(\left|A_{1} \times B_{2}\right|=1,00^{*}\right.$ and $\left.\left|B_{2} \times C_{3}\right|=-1,33^{*}\right)$ showed that self-fertilization did not have a pronounced effect on inbreeding depression, while crossbreeding with three plants improved flowering uniformity by increasing heterozygosity.

Table 4. Contrast values involving 33 populations with moderate and low-level inbreeding and characteristics related to onion plants and bulbs, and seed production



${ }_{1}^{1}$ Mean evaluations based on a grading scale from 1 to 9 , where 1 represents the lowest or worst values and 9 represents the highest or best values. $*$ Contrast estimate is significant according to the Scheffé test at $5 \%$ probability. 
Table 5. Operon primers used for the molecular characterization of the samples and related amplifications

\begin{tabular}{|c|c|c|c|c|c|}
\hline Nr. & Primer & Sequence $\left(5^{\prime}-3^{\prime}\right)$ & Nr. total bands & Monomorphic bands monomórficas & Polimorfism (\%) \\
\hline 1 & OPA14 & TCTGTGCTGG & 4 & 3 & 25.0 \\
\hline 2 & OPA16 & AGCCAGCGAA & 4 & 4 & 0.0 \\
\hline 3 & OPA17 & GACCGCTTGT & 6 & 6 & 0.0 \\
\hline 4 & ODP03 & GTCGCCGTCA & 4 & 4 & 0.0 \\
\hline 5 & OPE10 & CACCAGGTGA & 6 & 6 & 0.0 \\
\hline 5 & OPF19 & CCTCTAGACC & 3 & 3 & 0.0 \\
\hline 8 & OPC08 & TGGACCGGTG & - & - & - \\
\hline 9 & OPCO9 & CTCACCGTCC & - & - & - \\
\hline 10 & OPC11 & AAAGCTGCGG & - & - & - \\
\hline 11 & OPC13 & AAGCCTCGTC & - & - & - \\
\hline 12 & OPA15 & TTCCGAACCC & - & - & - \\
\hline
\end{tabular}

Resistance to Alternaria was higher when three plants were crossbred than when one plant was self-fertilized $\left(\left|A_{1} \times C_{3}\right|=-2.33^{*}\right)$ or when two plants were crossbred $\left(\left|B_{2} \times C_{3}\right|=-2.67^{*}\right)$. This may be partially explained given that resistance is governed by a dominant allele and that a greater number of parent plants would increase the probability of its presence. Resistance was not affected by the breeding method when the contrasts were performed on separate populations (populations with moderate and low-level inbreeding). This result may be a consequence of unsatisfactory sampling of qualitative characteristics. The literature does not provide results that can be directly compared with those of the current study. This is likely because the number of studies on this topic is limited by the relatively long period needed to carry out onion breeding. The populations in the current study were obtained from 2012 to 2013. However, the development of these plants took place from 2008 to 2011. Therefore, eight years were needed from inception to the final evaluation of the hypothesis that economically viable onion crops can be obtained from parent hybrids by mitigating the effects of inbreeding depression.

When the contrasts were performed separately on populations with moderate and low levels of inbreeding, average bulb weight, globular bulb percent and bulb yield were not affected by the different levels of inbreeding. In both cases, self-fertilization caused greater inbreeding depression, which favored lower levels for these three characteristics than crossbreeding with two and/or three plants.

The effect of inbreeding depression on general stem appearance and stem vigor was only noticeable when evaluating populations with an already moderate level of inbreeding. Reduced inbreeding depression in populations with low-level inbreeding can be explained by the high heterozygosity of self-fertilized plants $\left(F_{2} S_{1}\right)$ after only one generation of selffertilization.

\section{Polymorphism analysis using RAPD molecular markers}

The reproducibility of the results was determined using RAPD markers, which showed that out of 27 amplified fragments, only one was polymorphic (25\%). Some of the bands generated by the primers were easily detected, while others were nonspecific and therefore discarded. Seven of the thirteen primers did not anneal to the DNA strands and therefore could not be used for amplification. The remaining six primers allowed amplification of the DNA samples and generated mostly monomorphic bands. OPA14 was the only primer that produced a polymorphic band (Table 5).

Table 5 shows that there is low genetic diversity among the treatments, regardless of population, inbreeding level, or homozygosity level. Other authors have reported low genetic variability among onion lines. For example, Maniruzzanman et al. (2010) used RAPD markers to study variability among ten cultivars that had been crossbred from onion lineages and found that all ten cultivars were related. Shivnanajappa (2013) used 20 primers to investigate genetic relationships 
between male-sterile lines used to breed hybrids and found little genetic divergence between the cultivars. Nevertheless, germplasm is genetically distinct based on geographical origin (Mallor et al. 2014).

Studies on molecular associations in onion breeding programs have shown promising results (Saini et al. 2015, Patil et al. 2016, Ferreira and Santos 2018). Markers allow breeders to identify maintenance lineages quickly and effectively (Saini et al. 2015), optimizing the process of obtaining hybrids. Genetic similarity was observed between individual selffertilization and two- and three-plant crossbreeding, while agronomic evaluations showed that plant interbreeding induced significant increases in some agronomic characters. These data support the results of the current study and attest to the process of obtaining inbred lines by crossbreeding two and/or three plants without incurring genetic variability in the resulting population (based on six amplified RAPD markers), which may provide a promising method of obtaining onion lines without genetic divergence among individuals while maintaining distinguishability, homogeneity, and stability (DHS).

\section{CONCLUSIONS}

The effect of inbreeding depression is more pronounced in early generations, which are more heterozygous. Threeplant crossbreeding led to higher seed yield per plot in populations with low levels of inbreeding. The populations obtained from self-fertilization and two- and three-plant crossbreeding were genetically similar, demonstrating the efficiency of obtaining inbred lines without incurring genetic divergence.

\section{ACKNOWLEDGEMENTS}

To Coordenação de Aperfeiçoamento de Pessoal de Nível Superior - Brasil (CAPES - Finance Code 001) for sponsoring scholarship to the first author; the BASF Vegetable Seeds - Brasil, the Conselho Conselho Nacional de Desenvolvimento Científico e Tecnológico - Brazil (CNPq) and the Fundação de Amparo à Pesquisa do Estado de Minas Gerais (Fapemig) - Brasil for financially supporting this study.

\section{REFERENCES}

Ayroles JF, Hughes KA, Rowe KC, Reedy MM, Rodriguez-Zas SL, Drnevich JM, Cáceres CE and Paige KN (2009) A genome wide assessment of inbreeding depression: gene number, function and mode of action. Biological Conservation 23: 920-930.

Brewster JL (1994) Onions and other vegetables alliums. CAB International, Wallingford, 236p.

Devaux C, Lande R and Porcher E (2014) Pollination ecology and inbreeding depression control individual flowering phenologies and mixed mating. Evolution 68: 3051-3065.

Ferreira DF (2011) Sisvar: a computer statistical analysis system. Ciência e Agrotecnologia 35: 1039-1042.

Ferreira ME and Grattapaglia D (1996) Introdução ao uso de marcadores moleculares em análise genética. $2^{\text {nd }}$ edn, EMBRAPA-CENARGEN, Brasília, 220p.

Ferreira RR and Santos CAF (2018) Partial success of marker-assisted selection of ' $A$ ' and ' $B$ ' onion lines in Brazilian germplasm. Scientia Horticulturae 242: 110-115.

Hallauer AR, Carena MJ and Miranda Filho JB (2010) Quantitative genetics in maize breeding. Springer, New York, 663p.

Havey MJ and Kohn CV (2017) Efficacy of molecular markers Jnurf13 and AcPms1 for prediction of genotypes at the nuclear Ms locus in three open-pollinated populations of onion from North America. Hortscience 52: 1052-1053.
Khar A, Kumar A, Islam S, Kumar A and Agarwal A (2018) Genotypic response towards haploid induction in short day tropical Indian onion (Allium cepa). Indian Journal of Agricultural Sciences 88: 709-713.

Lee R, Baldwin S, Kenel F, McCallum J and Macknight R (2013) Flowering locus $T$ genes control onion bulb formation and flowering. Nature Communications 4: 2884.

Mallor C, Arnedo-Andres MS and Garces-Claver A (2014) Assessing the genetic diversity of Spanish Allium cepa landraces for onion breeding using microsatellite markers. Scientia Horticulturae 170: 24-31.

Maniruzzanman ME, Haque MM and Haque MA (2010) Molecular characterization of onion ( $A$. cepa $\mathrm{L}$ ) using RAPD markers. Bangladesh Agricultural Research 35: 313-322.

Nile A, Nile SH, Kim DH, Keum YS, Seok PG and Sharma K (2018) Valorization of onion solid waste and their flavonols for assessment of cytotoxicity, enzyme inhibitory and antioxidant activities. Food and Chemical Toxicology 119: 281-289.

Nunes RLC, Oliveira ABD and Dutra AS (2014) Agronomic performance of onion hybrids in baraúna, in the semi-arid region of Brazil. Revista Ciência Agronômica 45: 606-611.

Ouyang H, Hou K, Peng W, Liu L and Deng H (2017) Antioxidant and xanthine oxidase inhibitory activities of total polyphenols from onion. Saudi Journal of Biological Sciences 25: 1509-1513.

Patil YA, Dalvi VS, Borole VK, Krishna B, Dhake AV, Sane PV and Sane AP (2016) Molecular characterization of CMS lines in short-day white onions. Acta Horticulture 1143: 259-268. 
Petropoulos SA, Fernandes A, Barros L, Ferreira ICFR and Ntatsi G (2015) Morphological, nutritional and chemical description of "Vatikiotiko", an onion local landrace from Greece. Food Chemistry 182: 156-163.

Porcher E and Lande R (2013) Evaluating a simple approximation to modeling the joint evolution of self-fertilization and inbreeding depression. Evolution 67: 3628-3635.

Porcher E and Lande R (2016) Inbreeding depression under mixed outcrossing, self-fertilization and sib-mating. Evolutionary Biology 16: 1-14.

Quartiero A, Faria MV, Resende JTV, Figueiredo AST, Camargo LKP, Santos RL and Kobori RF (2014) Desempenho agronômico, heterose e estabilidade fenotípica de genótipos de cebola. Horticultura Brasileira 32: 259-266.
Saini N, Hedau NK, Khar A, Yadav Y, Bhatt JC and Agrawal PK (2015) Successful deployment of marker assisted selection (MAS) for inbred and hybrid development in long-day onion (Allium cepa L.). Indian Journal of Genetics and Plant Breeding 75: 93-98.

Schnable PS and Springer NM (2013) Progress toward understanding heterosis in crop plants. Annual Review of Plant Biology 64: 71-88.

Shivnanajappa D, Chinnappareddy LRD, Gowda V, Antharamiah SS and Chennareddy A (2013) The genetic relatedness analysis of male sterile and their maintainer lines of onion (Allium cepa L.) by using RAPD primers. Journal of Crop Science and Biotechnology 14: 85-95.

Vajire D, Thakare K, Solunke R, Panche A and Tiwari A (2017) The possibilities of the prediction of heterosis in elite lines of onion based on the assessment of genetic diversity. EC Microbiology 10.5: 211-219. 